\title{
Anesthetic Management in a Patient With Surgical Excision of Spinal Cords Hydatid Cyst: A Case Report
}

\author{
Faranak Behnaz $^{1^{* \mathbb{D}}}$, Nima Saeedi', Amir Saied Seddighi ${ }^{\circledR}$ \\ ${ }^{1}$ Department of Anesthesiology, Shohada Tajrish Hospital, Shahid Beheshti University of Medical Sciences, Tehran, Iran \\ ${ }^{2}$ Functional Neurosurgery Research Center, Shohada Tajrish Comprehensive Neurosurgical Center of Excellence, Shahid \\ Beheshti University of Medical Sciences, Tehran, Iran
}

\begin{abstract}
Echinococcosis granulosus is the leading cause of spinal hydatid disease. Hydatidosis of the bone happens in $0.5 \%-3 \%$ of all the cases: the involvement in the vertebral column is $50 \%$. In the endemic areas, one of the common causes of spinal cord compression is hydatid disease, and the diagnosis may remain obscure until specifying symptoms ensuing from complications due to root and cord compression. We present a case of recurrent spinal cords hydatid cyst in a 44 years old patient because it occurs rarely, and anesthetic management in such cases has never evaluated before.

Keywords: Echinococcosis granulosus; Hydatid disease; involvement of vertebral column.
\end{abstract}

\author{
*Correspondence to \\ Faranak Behnaz, Shohada \\ Tajrish Hospital, Shahid \\ Beheshti University of Medical \\ Sciences, Tehran, Iran \\ Tel: +982122741174; \\ Email: \\ faranak.behnaz@gmail.com \\ Published online September \\ 23, 2019
}

Citation: Behnaz F, Saeedi N, Seddighi AS. Anesthetic management in a patient with surgical excision of spinal cords hydatid cyst: a case report. Int Clin Neurosci J. 2019;6(4):163-165. doi:10.15171/icnj.2019.30.

\section{Introduction}

Hydatid cysts' infestation of humans caused by Echinococcosis granulosus or, more rarely, Echinococcus multilocularis. ${ }^{1}$ The endemic areas are South American, the Middle East, Australia, the Mediterranean, India, and China. ${ }^{2}$ Dogs and some wild carnivores like foxes are definitive hosts, while all mammals could be specific hosts, mainly sheep and cows. A person who comes in direct contact with the feces of an infected dog or consumes food and milk contaminated by dog feces, when eggs from the tapeworm passed in the feces (The fecal-oral route) may develop hydatid disease. ${ }^{1,3}$

Echinococcus granulosus is the leading cause of spinal hydatid disease. Hydatidosis of the bone happens in $0.5 \%-3 \%$ of all the cases: the involvement of the vertebral column is $50 \%$. The spinal involvements usually caused by direct extension from pulmonary or abdominal invasions and rarely begin primarily in the vertebral body. In the endemic areas, one of the expected causes of spinal cord compression is hydatid disease, and the diagnosis may remain obscure until symptoms ensuing from complications due to root and cord compression detect. ${ }^{4,5}$

General disease symptoms are radiculopathy, myelopathy, and local pain resulting in destructive bony lesions, pathological fracture, and consequential cord compression. ${ }^{6}$

Preoperative evaluation is necessary because the rupture and spreading of the cyst may result in anaphylaxis and recurrence. ${ }^{4}$

\section{Case Report}

A male 44 years old $(80 \mathrm{~kg}, 174 \mathrm{~cm})$ was admitted to the neurosurgery ward with complaints of recurrent spinal cords hydatid cyst. The patient had gone under the same surgery three times ten years ago. He was conscious, and his body temperature was $37.1^{\circ} \mathrm{C}$. Neurological examination revealed spastic paraparesis and hypoaesthesia. He had normal vital findings. His neurological examination and other systems were also regular. Lumbosacral magnetic resonance imaging (MRI) showed multiple extradural arachnoid cysts through the spinal canal and right L2 nerve root sleeve, compressing the thecal sac and its components (Figure 1).

The patient examined for more hydatid cysts in other organs. The abdominal ultrasonography (USG) was normal. The echocardiography (ECO) was normal with EF: 55\%. Thorax computed tomography (CT) was normal, too.

\section{Anesthetic Implications}

The patient was scheduled for surgery to excise the cysts and had a laminectomy performed through the posterior approach for neurologic decompression at the level of spinal involvement under general anesthesia.

Pre-operative assessments included electrocardiogram, heart rate, non-invasive blood pressure, and peripheral oxygen saturation established.

Anesthesia has induced via fentanyl $(200 \mu \mathrm{g})$, midazolam (2 mg), lidocaine (80 mg), and propofol (100 


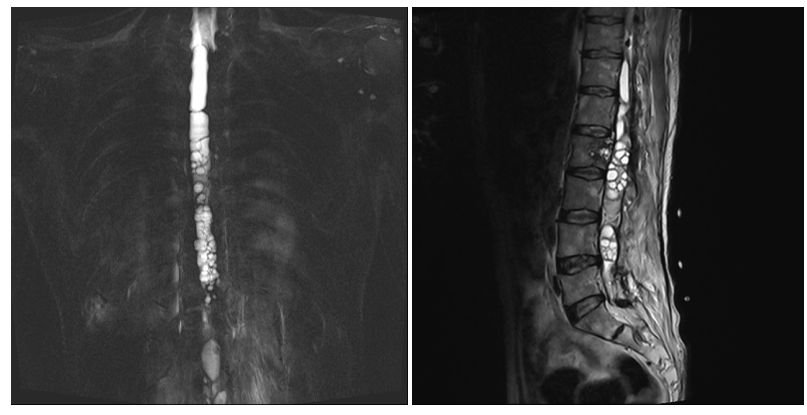

Figure 1. MRI showed multiple extradural hydatid cysts has seen through the spinal canal, which compresses the thecal sac and its components.

$\mathrm{mg})$. We prescript atracurium $(40 \mathrm{mg})$ then placed the orotracheal tube. Cardiac and invasive blood pressure (IBP) monitoring, pulse oximetry, capnometry, and intake/ output checking concluded.

Anesthesia has maintained with propofol infusion (4-6 $\mathrm{mg} / \mathrm{kg} / \mathrm{h}), \mathrm{O} 2: \mathrm{N} 2 \mathrm{O}$ (50:50), and atracurium as needed. Hydrocortisone (200 mg) administered and keeping ETCO 2 at 30-35 mm Hg. Due care was taken to prevent rupture while removing the cysts, epinephrine, atropine and sodium bicarbonate, dexamethasone, and salbutamol (inhaler) were available to treat anaphylactic reaction if it presented intraoperatively. The other hand surrounding the surgical field, was packed with mops to prevent local leakage. All the cysts extirpated without rupture (Figure 2).

However, scolicidal solutions, such as hypertonic saline and hydrogen peroxide, were not used during surgery to prevent chemical injury to the cord.

The postoperative period was fine, and the patient discharged after 5 days without any neurological deficit.

\section{Discussion}

The essential treatment is surgical and decompresses laminectomy with total excision of the cyst, whenever possible. ${ }^{1,7}$ Spinal hydatidosis compared to the spine's malignancy. However, the patients can have a healthy and satisfying life after the surgery. The risk of recurrence is $30 \%-40 \%$. Pre-operative use of scolicidal agents like hypertonic saline, $10 \%$ formaldehyde, $0.5 \%$ silver nitrate, and povidone-iodine is effective in preventing recurrences. Postoperative chemotherapy with mebendazole or albendazole has recommended for at least three months. Surgery might have to be repeated several times to eradicate the disease completely. ${ }^{4}$

The anaphylactic reaction is a systemic event that affects various organs and could be life-threatening. ${ }^{8}$ Anaphylaxis during anesthesia and the per-operative period is rare. Anaphylaxis can induce nausea, vomiting, urticaria, angioedema, bronchospasm, upper airway obstruction, cardiovascular collapse. The mortality rate due to anaphylaxis is between $3 \%-6 \% .^{9}$ During excisional

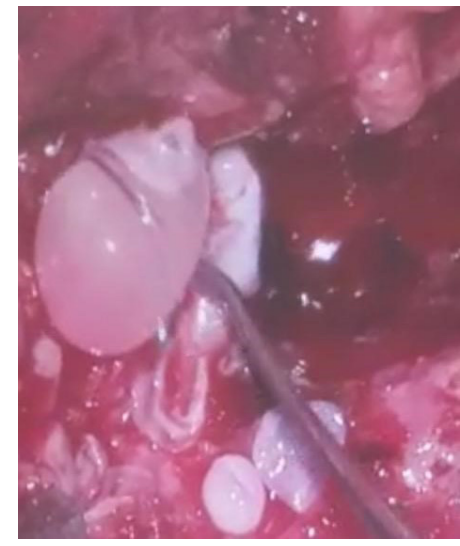

Figure 2. Surgical Excision of Spinal Cords Hydatid Cyst.

surgery, an anaphylactic reaction may occur after the rupturing of the cyst. The cause of the death in hydatid cyst rupture is due to anaphylaxis-related complications. ${ }^{2}$ The incidence of intraoperative anaphylaxis due to hydatid cyst reported as $0.2 \%-3.3 \%$, and it has mediated by Ig E-mediated type 1 hypersensitivity reaction. General anesthesia covers most of the clinical symptoms of anaphylaxis; urticaria, bronchospasm, hypotension, bradycardia are the main symptoms that can be observed. ${ }^{10}$ Massive fluid resuscitation (crystalloid/ colloid), vasopressor drugs (adrenaline, noradrenaline), glucocorticoids, $\mathrm{H} 1$, and $\mathrm{H} 2$ receptor blockers used in the treatment of anaphylactic reaction. If anaphylaxis develops, all medications and the operation should stop, and $100 \%$ oxygen treatment should start. The first-line treatment of perioperative anaphylaxis is epinephrine as a vasopressor. Glucocorticoids are used to reduce the late effects of anaphylaxis. ${ }^{11}$ Some studies reported that preoperative $\mathrm{H} 1$ and $\mathrm{H} 2$ receptor blockers are useful in hydatid cyst surgery to prevent anaphylaxis. ${ }^{1}$

\section{Conclusion}

The main goal of this case report is due to determine the general features of hydatid cyst disease and the anesthetic considerations and anaphylaxis prevention during the surgical treatment.

\section{Conflict of Interest Disclosures}

The authors declare that they have no conflict of interests.

\section{Ethical Statement}

An informed consent form for publication of the study obtained for the patient.

\section{References}

1. Izgi M, Solak MY, Uzun Ş, Bilginer B. Anesthetic management of a pediatric patient during surgical excision of primary cerebral hydatid cyst. Med Sci (Turkey). 2018;7(2):443-5. doi: 10.5455/medscience.2018.07.8799.

2. Uzun Ş, Canbay Ö, Aycan IÖ, Aypar Ü. [Ruptured Intracranial Cyst Hydatid; Anaphylaxis and Anaesthesia]. Turkiye Klinikleri J Anest Reanim. 2008;6(1):33-7. [Turkish]. 
3. Schnepper GD, Johnson WD. Recurrent spinal hydatidosis in North America. Case report and review of the literature. Neurosurg Focus. 2004;17(6):E8. doi: 10.3171/ foc.2004.17.6.8.

4. Gopal N, Chauhan S, Yogesh N. Primary spinal extradural hydatid cyst causing spinal cord compression. Indian J Orthop. 2007;41(1):76-8. doi: 10.4103/0019-5413.30531.

5. Arif $\mathrm{SH}$, Zaheer $\mathrm{S}$. Intradural extramedullary primary hydatid cyst of the spine in a child: a very rare presentation. Eur Spine J. 2009;18 Suppl 2:179-82. doi: 10.1007/s00586-008-07778.

6. Bhake A, Agrawal A. Hydatid disease of the spine. J Neurosci Rural Pract. 2010;1(2):61-2. doi: 10.4103/0976-3147.71715.

7. Alam S, Umer US, Gul S, Ghaus S, Farooq B, Gul F. Uncommon sites of a common disease--Hydatid cyst. J Postgrad Med Inst. 2014;28(3):270-6.
8. Panda NB, Batra Y, Mishra A, Dhandapani S. A giant intracranial hydatid cyst in a child: Intraoperative anaesthetic concerns. Indian J Anaesth. 2014;58(4):477-9. doi: 10.4103/00195049.139018.

9. Bensghir M, Fjouji S, Bouhabba N, Ahtil R, Traore A, Azendour $\mathrm{H}$, et al. Anaphylactic shock during hydatid cyst surgery. Saudi J Anaesth. 2012;6(2):161-4. doi: 10.4103/1658-354x.97031.

10. Davarci I, Tuzcu K, Karcioglu M, Yetim I, Aydogan A, Turhanoglu S. Anaesthetic management of anaphylactic shock caused by nonruptured hydatid cyst of the liver. West Indian Med J. 2014;63(5):545-7. doi: 10.7727/wimj.2013.090.

11. Kroigaard M, Garvey LH, Gillberg L, Johansson SG, Mosbech $\mathrm{H}$, Florvaag E, et al. Scandinavian Clinical Practice Guidelines on the diagnosis, management and follow-up of anaphylaxis during anaesthesia. Acta Anaesthesiol Scand. 2007;51(6):65570. doi: 10.1111/j.1399-6576.2007.01313.x. 